\section{THE BRITISH ENCYCLOPEDIA OF MEDICAL PRACTICE. Cumulative Supplement, 1939. Surveys and Abstracts, 1939.}

Edited by Sir Humphry Rolleston, Bart. Butterworth \& Co., Ltd. London. Price 25s. 0d.

In the review of the last volume of this excellent Encyclopædia we informed our readers that the Editor intended to keep the work up-todate by the publication of yearly supplementary volumes and these (as shown above) for 1939 have just appeared.

As the titles indicate the information is conveyed by three different methods:

(a) In the Cumulative Supplement there is provided a "post-script" to every article in the original volumes supplying any important facts on the subject which have become known since the original contributions were written.

(b) The Critical Surveys consist of short discussions of various subjects; most, though not all of which refer to articles in the original Encyclopædia. Some of these contributions might quite suitably have been incorporated in the Cumulative Supplement, since they review the most recent work done and views held on the subject being discussed. Others, however, pass in review the work of the last ten years. Some others tell the story since the beginning of the Century, while others again are prophetic in nature and hint at the developments which may be expected. But curiously, and that in spite of the varying periods reviewed, any references to the literature which are given are of papers published during the past two years.

(c) Abstracts of Medical Literature. This is the largest section of the series and supplies summaries of many important English and Foreign papers arranged under the headings employed in the volumes of the Encyclopædia.

In this way a great deal of valuable information is provided and by means of references to the articles in the original volumes of the Encyclopædia as well as cross-references to the contributions in the various supplementary volumes, the reader can easily obtain a comprehensive and up-to-date account of most problems throughout the fields of medicine, surgery, obstetrics and the different specialties.

The provision of all the information which the Editor wishes to lay before his readers is no easy task but we just wonder if the method he has adopted could not have been improved upon. We understand of course that the Cumulative Supplement is intended for temporary use only (for this reason it is bound simply in paper boards), and that the succeeding Supplements will contain all the facts detailed in the previous ones which have stood the test of time. Hence in size it must be kept within reasonable limits. But very many of the abstracts of current literature (which by the way is only a selection of what has appeared) will also be of only ephemeral interest and to our way of thinking could have been more suitably incorporated in the "post-scripts" of the Cumulative Supplement and submitted to annual pruning.
The one portion of the publication which is of more permanent value and deserves a really durable presentation is that providing the Critical Surveys. These, we hope, will be continued for they should be of particular educational value to the family doctor for whom the Encyclopædia has a special appeal. The surveys in the present issue, however, vary very much in their comprehensiveness; not a few of them are too much of the nature of a synopsis to provide much scope for real criticism.

\section{ILLUSTRATIONS OF ANATOMY FOR NURSES.}

By E. B. Jamieson, M.D. E. \& S. Livingstone. 1938. Price 7s. 6d.

These illustrations are taken from the Author's "Illustrations of Regional Anatomy," second edition, Parts VI and VII of which have been reviewed. The remarks made about the drawings in the above parts apply with equal force to the present set of illustrations.

A selection of 62 plates has been made, this selection was obviously a matter of extreme difficulty as the complete set of illustrations numbered some 275 plates, but on the whole this task has been well performed.

The work suffers, as it must inevitably do, considering its origin, from unnecessarily great detail in some regions, and too little in others.

If used to supplement the illustrations of a recommended text book these excellent drawings should prove very helpful in stressing the three dimensional aspect of the subject.

\section{ANGINA PECTORIS.}

By Heyman R. Miller. Baillière, Tindall \& Cox. 1939. Price 15s. Od.

This book provides an exceedingly full survey of the anatomical and physiological basis for the transmission of impulses causing cardiac pain. The routes followed are portrayed by a number of very clear and full diagrams.

In addition, a very complete study is made of the non-cardiac conditions which may simulate anginal pain. There is one omission from the list, pneumo-thorax, in which severe left-sided pain with dyspnœa, shock and tachycardia may occur.

There is, however, rather a striking absence of any attempt to classify clinically the various types of pain. That of coronary infarction is usually very different from that of angina of effort. Nor is the large group of patients with cardiac, but non-coronary pain, adequately dealt with.

There is a brief reference to the subject on page 159 , but no clinical description of what is a very common condition.

A further criticism is the loose application of the form angina, to cover coronary infarction. 
This results in a confusion of ideas, so that a reader not well acquainted with various conditions might well assume that the commonest cause of pain, angina of effort, is often fatal in the attack. Such terms as "the peril of a paroxysm," used on page 12, which are common in the book, give the impression that attacks are frequently fatal, when statistically the exact opposite is the case, death hardly every occurring in such an attack.

A final minor point is the statement on page 23 that "apnœa" is usual in "classical" angina pectoris. The opposite is surely true, for the associated coronary disease as often as not produces some dysponœa with the pain. The book, however, is very complete, and the reference tables are full. It is bound to be of great use to all those interested in the subject.

\section{SAVILL'S SYSTEM OF CLINICAL MEDICINE.}

Edited by Agnes Savill, M.D. and E. C. WARNER, M.D., F.R.C.P. 11th Edition. Edward Arnold, Ltd. London. 1939. Price 28s. Od.

We are very pleased to see another edition of this book which is an old friend to many of us.

The method of approach, as mentioned in the Preface, is rather different to that found in most textbooks of medicine for the clinical aspect is emphasised and certainly for the most students, as also for a great many practitioners, this method simplifies study and makes references more accessible. It is a great testimony to the advances made in medicine that so much of the book has had to be rewritten, although the last edition was revised in 1936.

It is somewhat doubtful whether the first chapter entitled "Clinical Methods" is really essential, as it deals more or less with elementary principles of clinical examination. The chapter on Electrocardiograms is short but good; and particularly to be commended is the chapter dealing with aneurysm of the aorta and other intrathoracic tumours.

Possibly some of the book really needs reconsideration in the light of modern views and particularly perhaps the very hard and fast differences which are laid down between such conditions as lobar-pneumonia and bronchopneumonia. It is more usual nowadays to regard infection of the lungs as a whole and not to make these distinctions so emphatic.

It has been possible to shorten the book a little by referring readers, where necessary, to special textbooks and this is a very good plan as it tends to simplify the reading. For instance, surgery of pulmonary tuberculosis only occupies one small paragraph and it is quite evident that this will suffice for the ordinary reader. The chapter on the spleen is very short and only occupies eight pages and of these over two deal with the physical examination. Diseases with which enlargement of the spleen is associated are naturally dealt with in full elsewhere. Chronic joint diseases, which are always such a trouble in textbooks, are dealt with simply but adequately.
It must be admitted that any book which tries to cover such an enormous amount of ground must fall down in detail and one is inclined to doubt whether the place which these books have occupied in the past will be available for them in the future. Nevertheless, as things are now, books of this type with a long history behind them are needed; and of these books "'Savill's System of Clinical Medicine" is at least as good as and in many respects superior to the great run of them.

\section{TEXTBOOK OF MEDICAL TREATMENT.}

By D. M. Dunlop, L. S. P. Davidson and J. W. MCNeE. E. \& S. Livingstone. 1939. Price 25s. Od.

This is a new book on Treatment emanating from the principal Schools of Medicine in Scotland. As would be expected from the downright Scot, some attempt is made in this book to be absolutely definite on the value of various methods of treatment. It is a very large book and runs into nearly 1,100 pages, so that all varieties of treatment are mentioned, including a final chapter on technical procedures and oxygen therapy.

In spite of its length the subject matter is not easy to read in some sections and to practitioners who are not familiar with certain modern contentions, it tends to be rather confusing. For instance, the chapter on diseases of the ductless glands might more simply have been started with an introduction dealing with the general coordination of these glands and the effect which one has on another; and so given a sort of general survey of the endocrine problem in simple language. This would have given the practitioner an idea as to how it was thought the endocrine system worked and would have simplified the discussion of such things as the gonadotropic hormones and given point to such small paragraphs as that on the basophile adenoma with which it is said that Cushing's Syndrome is associated. As the subject was being discussed not only from the treatment point of view, it might also have made it simpler if Cushing's Syndrome had had a small paragraph to itself and mention had been made that it is not always associated with basophile adenoma and that, in fact, it has been described with entirely different pathology.

It may seem that these criticisms, mild though they be, are not sufficiently important to be introduced, but it is felt that, good as the book is, a little more simplification and a little more practical re-arrangement would make it much better.

The question of treatment of cardiac conditions should nowadays give some indication of the electrocardiographic control which is necessary in certain states and suitable curves should be shown, especially of such definite conditions as coronary thrombosis. Although mention is made of all the essential factors, this is not brought out very well.

On the whole the book is a good one, well reproduced, and well set out. 